PUPIL: International Journal of Teaching, Education and Learning

ISSN 2457-0648

Susantiningdyah et al., 2022

Volume 5 Issue 3, pp. 203-219

Received: 27th August 2021

Revised: 07th December 2021, 31 st January 2022, 03 ${ }^{\text {rd }}$ February 2022

Accepted: 04 ${ }^{\text {th }}$ February 2022

Date of Publication: 07th February 2022

DOI- $h$ ttps://doi.org/10.20319/pijtel.2022.53.203219

This paper can be cited as: Susantiningdyah, H., Inayati, N., Dirgantari, A. C. E AS, C. H. (2022). Using Collaborative Learning Approach to Improve Learner's Mental Lexicon of Word Association. PUPIL: International Journal of Teaching, Education and Learning, 5 (3), 203-219.

This work is licensed under the CreativeCommons Attribution-NonCommercial 4.0 International License. To view a copy of this license, visit http://creativecommons.org/licenses/by-nc/4.0/ or send a letter to Creative Commons, PO Box 1866, Mountain View, CA 94042, USA.

\title{
USING COLLABORATIVE LEARNING APPROACH TO IMPROVE LEARNER'S MENTAL LEXICON OF WORD ASSOCIATION
}

\author{
Healty Susantiningdyah \\ Language and Culture Hub, Institut Teknologi Kalimantan, Balikpapan, Indonesia \\ susan@lecturer.itk.ac.id \\ Nina Inayati \\ English Department, University of Muhammadiyah Malang, Malang, Indonesia, \\ ninainayati@gmail.com

\begin{abstract}
Alfi Suci Dirgantari
Language and Culture Hub, Institut Teknologi Kalimantan, Balikpapan, Indonesia alfisuci@lecturer.itk.ac.id

Hilga Clararissa AS

Language and Culture Hub, Institut Teknologi Kalimantan, Balikpapan, Indonesia hilgaclara@lecturer.itk.ac.id
\end{abstract}

\begin{abstract}
A collaborative learning approach has been identified to lessen anxiety and allow more comprehensible inputs to be processed cognitively to result in meaningful outputs. This study specifically examines the effectiveness of the collaborative learning approach and its best fit model supplemented with several techniques to improve students' mastery of the mental lexicon
\end{abstract}


of the word association. This Classroom Action Research involved 60 college students in their senior years in Institut Teknologi Kalimantan. The data collection involved two cycles in which each cycle employed planning, implementation, analysing learning activities and learning outcome and finally reflection. To gain insight through each cycle, a cloze test and a survey were administered. Furthermore, the result was analysed qualitatively and the finding reveals a significant improvement in terms of the mental lexicon of word association repertoire especially in cycle 2. The percentage of the students meeting the criteria of success doubled at 71.67\% while the students' learning perception throughout each cycle was successfully maintained. Collaborative learning also helped most students to create a positive perception to level up their mental lexicon mastery.

\section{Keywords}

Collaborative Learning Approach, Language Acquisition, Mental Lexicon, Word Association, Student's Perception

\section{Introduction}

Online instruction has become the norm in education amid and most likely post-Covid19 pandemic. Online learning, a form of distance learning, has several characteristics that distinguish it from offline face-to-face classroom settings (Wong et al., 2019). This requires teachers and learners to several adjustments and compromises, one of which is in how to support the learning process through the use of collaborative learning designs. Collaboration plays a key role in language learning as it allows real and natural interaction to take place, a concept serving as one of the core elements of communicative language teaching and learning (Salma, 2020). Collaborative language learning enables authentic use of the language in natural settings. In other words, when learners are engaged in small group work to finish a project, they are engaged in active language production which could train and strengthen their linguistic repertoire, thus also reinforcing their mental lexicon.

Reflecting on the current English language proficiency trend during the pandemic, English has become the spotlight subject in Institut Teknologi Kalimantan (ITK). As an emerging state institute, ITK strived for implementing the most effective yet convenient learning methods in all enrolled courses, especially English. Due to the high standard of higher education qualifications as well as workforce demand, ITK's senior students must graduate with a minimum upper intermediate level of English while their current English mastery was generally at the elementary level. This gap certainly occupies serious attention and requires 
rapid action. To maximize the learning outcome eclecticism is considered pivotal, especially the one which brings more engagement, systematic impact and positive personal perception.

\subsection{Scope and Gap Identification}

Studies about online collaborative learning in English language instruction have generally shown positive results; it is deemed to allow rich language input, diverse learning tasks, the less lecturing burden for teachers, and improved interests in learning (Arnold \& Ducate, 2019; Dooly \& Sadler, 2016; Tsai, 2019). A study by Mohammed et al (2020) also suggests that online collaboration offers high potential to engage students to learn and practice the language beyond classroom settings. Involving Malaysian and French English language learners in e-collaboration settings, they found equal partnerships among the two groups, which boost their confidence and reduce anxiety, thus creating a meaningful language learning experience. With such benefits, collaborative learning is deemed beneficial in boosting learners' mental lexicon when learning about word association.

However, there is a limited number of studies explaining how collaborative learning and mental lexicon come together in the form of classroom action research. To understand the cognitive process during word association learning, Second Language Acquisition (SLA) takes a key role. One of the hypotheses points out that comprehensible input allows learners to gain more benefits to second language learning. The focus of this study posits on creating a collaborative learning atmosphere based on the reflection of the four-model hypothesis proposed by Krashen's and how each model results in the improved students' mastery of word association as well as their positive learning perception.

A current research trend is situated specifically on how ICT use impacts learners' perception of emotion that is indicated through the lexicon availability. Salcedo-Lagos, et al. (2021) claims that there is a significant difference in the perception of emotion due to ICTs use, and the result of his study concludes that there is only positive emotion in the research participants' mental lexicon. However, the result is restricted to describing the mental lexicon web and how it relates to non-language pedagogy variables based on teachers' perspectives. Therefore, it is necessary to describe the perception of emotion from the other side that is from the students' point of view.

\subsection{Research Objectives}

The objective of this research is to explain how a collaborative approach benefits the lexicon storage process. Based on psycholinguistics and language pedagogy, this study investigates how the mental lexicon is wired into the students' cognitive development. It also tries to fill the gap within the current research trend by offering more options for collaborative 
approaches to be applied within an online setting where the student's positive learning perception becomes one of the parameters of success. As such, deeper understanding and discussion about collaborative learning and mental lexicon are considered necessary.

\section{Literature Review}

Reviewing syntax collaborative learning, its setting requires learners to work in small groups to accomplish a specific task. As they do that, they work together with their peers and engage in an active search formed understanding that benefits their learning process (Salma, 2020). Collaborative learning stems from the constructivism theory of education proposed by Vygotsky (1980). The theory posits that learning takes place as learners interact with their peers and environment. In other words, learners improve their understanding by adding one block of knowledge to their previous ones, and by continuously testing their newly acquired knowledge and understanding through critiques, acceptance and rejection to its relevance (Robinson, 2017). When working together, learners as a group 'construct knowledge' by 'collaboratively creating a culture of shared meaning' (Barkley et al., 2014, p. 17).

With the current development where education has hugely embraced technology, collaborative learning still maintains its relevance as collaborative practices in classroom contexts frequently involve technology to enhance learners' interactive experience (So \& Brush, 2008). Studies have shown that learners learn more effectively when collaborating with their peers, both in offline and online instruction settings (Pattanpichet, 2011; Reychav, 2017; Wentzel \& Watkins, 2002). However, online settings which have different characteristics to that of offline ones require additional support. For example, a study by Robinson (2017) maintains that in an online learning context, group work needs further support to create a meaningful online collaborative learning experience. Such supports include longer and more flexible time, nurturing and scaffolding instructional design, and aiming for learners' comfort when working together in online settings.

In foreign or additional language learning contexts, collaborative and cooperative learning holds a key role in developing learners' communicative competence (Salma, 2020). Communicative competence, which is the core of communicative language teaching and learning, is characterized by learners' interaction, which is also a key component in collaborative learning. Meaningful interaction among peers in a collaborative format is believed to benefit learners as it helps reduce stress and anxiety, and promotes a relaxed environment for learning, reducing peer pressure and encouraging better achievement (Salma, 
2020). More importantly, constructive interaction during collaboration among peers allows meaningful use of the language learned, enabling learners to experiment with their newly acquired linguistic components.

Furthermore, the mental lexicon itself is the organization of words stored in long-term memory. Carroll (2008) claims that word association indicates whether the new words are stored in the long-term memory. In psycholinguistics, to examine the structure of the mental lexicon model within someone's cognition, lexical relation needs to be identified. Similarly, the mental lexicon can be seen figuratively as a dictionary (Peppard, 2007), as well as a worldwide web (Brown in Peppard, 2007). Mental lexicon, in fact of flexible arrangement in such order with clear grouping, traceable network and it develops at any time. Referring to a worldwide web, a mental lexicon is built up through three stages respectively in cognition, starting from the input, storage and retrieval.

\section{Methods}

This study employs an action research design. As commonly occurs in the education area, the current study set the action research in the classroom settings of English language teaching and learning, hence called Classroom Action Research. In teaching, action research aims to improve the practice and outcomes of teducationalion practices, such as the teachers, methods or media used in teaching (Hidayati, 2010). In this case, the current study's goal is also to improve the practices and outcomes related to the students' mental lexicon with a specific focus on word associations. To achieve the goal, this research proposes the use of a collaborative approach with suggestopedia and task-based language teaching used as specific teaching methods. Both methods were chosen due to their collaborative nature and their suitability to the teaching objectives. Besides, the use of more than one collaborative method was believed to minimize boredom among students.

Following the syntax of action research, cycles of planning, action, observation and reflection were employed in this study. In the first stage of planning, the researchers, some of whom were the class teachers, designed the teaching materials and collaborative activities and devised the instruments used to investigate the achievement of the study's indicators of success. Then, the teaching plans were implemented and the activities and students' responses were observed, which made up the action and observation stages. Finally, in the last stage of reflection, data from the teaching observation were analysed to see whether all the indicators 
of success were achieved or not. The cycle was considered enough once all the indicators of success were met.

The subjects of the current study were the students of English major, the academic year 2019-2020. They were chosen because of two reasons. First, being students of the second year, they are in a critical time absorbing and retaining the English lexicon as much as possible. However, initial observation shows that many students seem to face great challenges about how to learn, store and produce the newly learned lexicon in their speaking or writing. Second, as second-year students, adjustment problems were not a challenge anymore as they had experienced at least two to three semesters of studying in a higher education setting, thus they were deemed to be able to focus better to learn foreign languages.

There are two criteria of success employed in this study. First is the class's mean score of 75, with no student score below 70. Second, the students' generally positive perception of the class activities, proven by a minimum of $70 \%$ of students expressed agreement and enjoyment towards the teaching and learning activities. As such, the data collection techniques used with regards to the achievement of the success indicators are also two-fold; first, the vocabulary test to measure students' English lexicon improvement, and second is a survey of students' perception towards the teaching and learning activities. In addition, the data on how the teachers carried out the teaching and learning activities were obtained in the form of the teachers' reflection and observation and are presented narratively.

To analyze the data, this study employed descriptive statistics. First, the student test results were analyzed using the central tendency techniques namely frequency, means and percentage. Second, the survey data were analyzed using weighted means to calculate the general perception of all the students about the methods used during the teaching and learning process.

\section{Results}

Through direct observation and cloze tests, several key points generate the students' learning perception as well as their learning outcome. Table 1 succinctly describes the overall comparison of results in cycles 1 and 2 .

Table 1: Students' learning outcome and perception in cycles 1 and 2

\begin{tabular}{|l|l|l|l|l|}
\hline No. & Aspects & Cycle 1 & Cycle 2 & Improvement \\
\hline 1. & $\begin{array}{l}\text { Teaching } \\
\text { methods }\end{array}$ & $\begin{array}{l}\text { Collaborative } \\
\text { approach } \\
\text { supplemented with } \\
\text { Suggestopedia }\end{array}$ & $\begin{array}{l}\text { Collaborative } \\
\text { approach } \\
\text { supplemented with }\end{array}$ & $\begin{array}{l}\text { Noticeable } \\
\text { Participation And } \\
\text { Engagement }\end{array}$ \\
\hline
\end{tabular}




\begin{tabular}{|l|l|l|l|l|}
\hline & & & $\begin{array}{l}\text { task-based } \\
\text { technique }\end{array}$ & \\
\hline 2. & Mean score & 66 & 77 & $\begin{array}{l}\text { The Increasing } \\
\text { Number Of Correct } \\
\text { Answers On } \\
\text { Vocabulary Test }\end{array}$ \\
\hline 3. & The lowest score & 20 & 64 & $\begin{array}{l}\text { The Increasing } \\
\text { Number Of Correct } \\
\text { Answers On } \\
\text { Vocabulary Test }\end{array}$ \\
\hline 4. & $\begin{array}{l}\text { The percentage } \\
\text { of students } \\
\text { passing the } \\
\text { criteria of success }\end{array}$ & $32 \%$ & $\begin{array}{l}\text { The Increasing } \\
\text { Number Of Correct } \\
\text { Answers On } \\
\text { Vocabulary Test }\end{array}$ \\
\hline 5. & $\begin{array}{l}\text { Student's positive } \\
\text { perception } \\
\text { (Grand weighted } \\
\text { mean in } \\
\text { percentage) }\end{array}$ & $79.2 \%$ & $71.67 \%$ & $\begin{array}{l}\text { The Increasing Use } \\
\text { Of Collocation And } \\
\text { Figurative } \\
\text { Expressions In } \\
\text { Written And } \\
\text { Speaking Task }\end{array}$ \\
\hline
\end{tabular}

Source: Student' score rooster on cloze tests and student's learning perception survey in

cycles 1 and 2

During the preparation stage in cycle 1, the researcher planned to combine a collaborative approach with suggestopedia to facilitate the students' learning about daily collocation with a certain number of figurative languages. The designated meetings in cycle 1 consisted of 3 days (sessions) in which each session took 100 minutes and was attended by 6268 students. The main purpose of the first cycle is to engage the students in a positive environment through ice breaking, sharing background knowledge, improving their confidence as well as building their motivation to learn English during this program.

Next, the implementation stage in cycle 1 includes two main activities. Firstly, the students were given modelling and practices. Subsequently, in the main activity, they listened to a song and were asked about their personal feelings afterwards. In addition, they were also instructed to write several phrases they remembered as well as the message they perceived from the song. Later, a group of students presented a song to their peers and in turn, their peers evaluated the presenters as well as answered a quiz for collocation summary.

Table 2: The Use of Collocation in Their Song Report in Cycle 1

\begin{tabular}{|l|l|}
\hline \multicolumn{2}{|c|}{ Day 1-Song A } \\
\hline Collocation & $\bullet$ Lift Him Up \\
\hline Figurative Language & $\bullet$ You Could Beat The World \\
& $\bullet$ You Could Talk To God \\
\hline \multicolumn{2}{|c|}{ Day 2- Song B } \\
\hline
\end{tabular}




\begin{tabular}{|c|c|}
\hline Collocation & $\begin{array}{ll}\text { - } & \text { Raise Me Up } \\
\text { - } & \text { Getting Out From } \\
\text { - } & \text { Count On Me } \\
\text { - } & \text { I Used To Be } \\
\text { - } & \text { Start Over } \\
\end{array}$ \\
\hline & Day 3- Song C \\
\hline Collocation & $\begin{array}{ll}\text { - } & \text { Waiting Up } \\
\text { - } & \text { Did It My Way } \\
\text { - } & \text { Knock Us Down } \\
\text { - } & \text { Ain't Gonna Live Forever } \\
\text { - } & \text { Wanna Go } \\
\text { - } & \text { Fall Down } \\
\text { - } & \text { Looking For } \\
\text { - } & \text { Take As I Am } \\
\text { - } & \text { Get Back Up } \\
\text { - } & \text { Give It All }\end{array}$ \\
\hline Figurative Language & $\begin{array}{ll}\text { - } & \text { The Brightest Lights Fill My Head } \\
\text { - } & \text { My Heart Is Like An Open Highway } \\
\text { - } & \text { Just Let Them Bark } \\
\text { - } & \text { Walk The Wire For You } \\
\text { - } & \text { Heal The World } \\
\text { - } & \text { Through The Dark } \\
\text { - } & \text { My Heart Feels Like December }\end{array}$ \\
\hline
\end{tabular}

(Source: Teacher's observation sheet in cycle 1)

From the data, it was obvious that the students did not get many collocations. They got only one collocation in one song with additional figurative language. Throughout the other two meetings, the students gained more insight towards the song as they listened, and their curiosity grew as well as the number of collocations they identified. In the second meeting, the students remained to ask about the concept of collocation and they wrote many direct quotes from the song lyrics as a whole sentence. They improved their collocation resources in meeting 2 and meeting 3. Surprisingly, by the addition of question ques in their assignment, their collocation and figurative language resources improved.

Finally, at meeting 4 the evaluation was administered. The result showed that the average score of the students was significantly below the criteria of success set up, it was 66 . Likewise, the lowest score was found at 20 far beyond the criteria of success which was 70 . Overall, the percentage of the students passing the criteria of success was less satisfactorily reaching $32 \%$. This indicates that the first cycle needs to be improved in terms of delivery techniques and content.

Meanwhile, a students' perception survey was delivered at the end of cycle 1 . The number of students enrolling in the evaluation was 66 respondents, and they were given two types of questions, closed questions and open questions. The following table presents students' 
perception of the teaching method in cycle 1 and their answers rated using the Likert scale as follows: Highly agree (4), Agree (3), Disagree (2), Highly disagree (1).

Table 3: Closed Question Responses in Cycle 1

\begin{tabular}{|c|l|l|}
\hline 1 & I can answer most questions in the test after learning using method A. & 3,03 \\
\hline 2 & Method A allows me to learn new vocabulary/collocation in context. & 3,29 \\
\hline 3 & $\begin{array}{l}\text { Method A allows me to learn new vocabulary/ collocation } \\
\text { communicatively }\end{array}$ & 3,20 \\
\hline & $\begin{array}{l}\text { Method A allows me to learn new vocabulary/ collocation } \\
\text { collaboratively }\end{array}$ & 3,18 \\
\hline 5 I think method A is effective for learning new vocabulary/collocation. & 3,21 \\
\hline 6 I found Method An easy to follow. & 3,12 \\
\hline 7 Using Method A, I can generally understand the material better. & 3,05 \\
\hline 8 Generally, I enjoy the learning activities using Method A. & 3,29 \\
\hline 9 In the future, I'd like Method A to be used again. & 3,21 \\
\hline & Grand weighted mean & $\mathbf{3 , 1 8 =}$ \\
\hline
\end{tabular}

(Source: Student's learning perception survey in cycle 1)

Meanwhile, based on table 4, the students were asked to describe the effectiveness of the teaching method and the ways how to improve its effectiveness based on their personal experiences through open questions.

Table 4: Open Question responses in Cycle 1

\begin{tabular}{|r|l|l|}
\hline No & Suggestion & frequency \\
\hline 1 & Face To Face & 3 \\
\hline & $\begin{array}{l}\text { More Active Direct Communication/ Focus More } \\
\text { On Speaking-Reading Etc/ Make Students More } \\
2\end{array}$ & \\
\hline 3 & Vartive/ Follow With Vocab Games & 13 \\
\hline & & 4 \\
\hline 4 & Good Enough, No Suggestion & $\begin{array}{l}11 \text {, Cause All Likes Music, } \\
\text { Really Helpful For } \\
\text { Learning Vocab, Effective } \\
\text { Enough }\end{array}$ \\
\hline & & $\begin{array}{l}\text { All Turn On Video 1 } \\
\text { Find Strong Network 1 } \\
\text { Clarify The Timetable 1 } \\
\text { Clarify The Instruction 5 }\end{array}$ \\
\hline 5 & Technical & 6 \\
\hline 6 & Focus More On Increasing Vocab. E.G Bahas Lirik & 6 \\
\hline 7 & Add Discussion About Other Aspects, E.G. Tenses, & \\
\hline & Register & 7 \\
\hline
\end{tabular}

(Source: Student's learning perception survey in cycle 1)

The students' general perception in cycle 1 shows that they expressed general contentment towards the use of the first method. The closed items' Likert Scale data shows that the students' general enjoyment towards the method and materials used in this cycle was $79,5 \%$, indicated by the grand weighted mean of 3,18 from the maximum of 4 points (1: Poor 
enjoyment - 4: high enjoyment). Looking into the detail of the questionnaire items, the three items with the highest means indicates that the method used in this cycle was enjoyable and afforded students to learn more about new collocations contextually. As for the open items where students were invited to suggest some improvements, 11 of them commented that the method was effective enough in helping them to learn new collocations, while 13 of them suggested that the method be followed by more active communication activities among students, such as those focusing on speaking, reading or vocabulary games. To sum up, the students' general perception of the method used in the first cycle has reached the $70 \%$ threshold targeted for success.

Based on the reflection in cycle 1, cycle 2 refined the collaborative learning approach by using tasks in four different skills. The researcher planned for three meeting sessions and selected reading materials from the upper intermediate level with general topics. Cycle 2 also includes preparing the instructional media consisting of a reading task which was delivered online through their e-learning and a zoom application to facilitate the online meeting. Next, breakout rooms were opened to let the students discuss with their peers comprehension questions, vocabulary practices, as well as critical thinking questions. During the group discussion, the students were also allowed to share their interpretation of the text in their native language as well as to make notes to the unfamiliar vocabulary. Later on, in the main room, they were asked to highlight words that came together in phrases (collocation) completed with their meaning in their first language according to their overall interpretation of the text.

Next, the implementation stage began with delivering a variety of treatments which mainly focused on collaboration with a variety of tasks. The activity in meeting 1 included active listening and speaking where the students listened to lecture audio and then they were asked to outline a summary as well as to identify collocation from the audio text. The students were also required to discuss their summary and collocation finding with their group. In the second meeting, the students worked collaboratively in a group to figure out a summary of another audio text. However, in the second session, the students were encouraged to present their group work using a slideshow. In the third meeting, the students worked on a reading text where they examined not only the word meaning but also comprehension questions.

The students seemed to perform more enthusiastically on the reading text rather than on audio text. They also performed quite a gooteamworkrk on identifying collocation and answering comprehension questions whenever it came to a reading passage. In terms of technicality, listening comprehension contributed another difficulty level for them, since they 
had limited model exposure for pronunciation and unfamiliarity toward native speakers' accents Therefore, they missed a rather significant amount of information.

Table 5: Students' collocation enquiry on a reading task on cycle 2

\begin{tabular}{|clll|}
\hline No. & Day 1 & Day 2 & day 3 \\
\hline 1 & Mount To & Recounted & Ceasing \\
\hline 2 & Overworked & Ceasing To & Disposed \\
\hline 3 & Out-Patient & Indisposition Of & Mounting \\
\hline 4 & Ask For & In Charge Of & Overworked \\
\hline 5 & Provide Someone With & Ask For & Fervently \\
\hline 6 & In Charge Of & Out-Patient & Appreciated \\
\hline 7 & Ceasing To & Little Appreciated & In Charge \\
\hline 8 & - & Dispose Of & Ask For \\
\hline 9 & - & Mount To & Putting Up \\
\hline 10 & - & - & Comforted \\
\hline 11 & - & - & Indisposition Of \\
\hline
\end{tabular}

(Source: Teacher's observation sheet in cycle 2)

Table 5 describes the students' mental lexicon performance which was observed and assessed. A reading task was employed and combined with collaborative learning to gain collocation mastery. Collaborative learning remained the focus of the activity throughout the whole cycle by letting the students work in a group.

The results of the activity on day 1 shows that there were only 7 common phrases (collocation) that most students were able to identify. Furthermore, on day 2 the same activity was delivered, only that the main room discussion was extended with guidance from the teachers. The quiz result on day 2 shows a slight progression that more pair-words were acquired by most of the students. Subsequently, on day 3 after the cloze test was administered, the result shows most of the students were able to identify collocations in the text correctly.

Finally, the overall evaluation in cycle 2 depicts improvement toward collocation enquiry compared to cycle 1 . The test result in cycle 2 shows a significant rise in mean scores compared to the previous cycle. The mean score in cycle 2 was 77 , moderately surpassing the criteria of success which was 75. In addition, the percentage of the students passing the threshold score was approximately more than two times bigger than the previous gain at $32 \%$. However, in cycle 2 there were still few students whose score was below the threshold, ranging from 75 to the lowest score at 64 .

In terms of positive perception in cycle 2, there were some extended measures addressed through the closed and opened questions, namely, comparisons among teaching techniques and also the students' suggestions about improvement towards learning activities to 
reach its maximum potential result. The following table presents the student's response summary on close and open questions.

Table 6: Close Questions in Cycle 2

\begin{tabular}{|c|c|c|}
\hline No & Statement & Weighted Mean: 1-4 \\
\hline & $\begin{array}{l}\text { I Learn A Lot Of Vocabulary/Collocation By Using } \\
1 \text { Method A. }\end{array}$ & 3,17 \\
\hline & $\begin{array}{l}\text { I Can Answer Most Questions In The Test After } \\
2 \text { Learning Using Method A. }\end{array}$ & 3,02 \\
\hline & $\begin{array}{l}\text { Method A Allows Me To Learn New } \\
3 \text { Vocabulary/Collocation In Context. }\end{array}$ & 3,29 \\
\hline & $\begin{array}{l}\text { Method A Allows Me To Learn New Vocabulary/ } \\
4 \text { Collocation Communicatively }\end{array}$ & 3,21 \\
\hline & $\begin{array}{l}\text { Method A Allows Me To Learn New Vocabulary/ } \\
5 \text { Collocation Collaboratively }\end{array}$ & 3,21 \\
\hline & $\begin{array}{l}\text { I Think Method A Is Effective For Learning New } \\
6 \text { Vocabulary/Collocation. }\end{array}$ & 3,16 \\
\hline & 7 I Found Method An Easy To Follow. & 3,05 \\
\hline & $\begin{array}{l}\text { Using Method A, I Can Generally Understand The } \\
8 \text { Material Better. }\end{array}$ & 3,17 \\
\hline & $\begin{array}{l}\text { Generally, I Enjoy The Learning Activities Using } \\
9 \text { Method A. }\end{array}$ & 3,29 \\
\hline & 10 In The Future, I'd Like Method A To Be Used Again. & 3,09 \\
\hline & Grand Weighted Mean & $3,17=79,2 \%$ \\
\hline
\end{tabular}

(Source: Student's learning perception survey in cycle 2)

Table 7: Open responses in Cycle 2

\begin{tabular}{|c|l|l|}
\hline No & Suggestion & Frequency \\
\hline 1 & Face To Face & 2 \\
\hline 2 & $\begin{array}{l}\text { More Active Direct Communication, E.G. Follow } \\
\text { With Vocab Games (E.G In Quiz) }\end{array}$ & 11 \\
\hline 3 & Vary The Song Types, Add More Songs & 2 \\
\hline 4 & Good Enough, No Suggestion & $\begin{array}{l}\text { 17 E.G. Add My Vocab, } \\
\text { Train Listening }\end{array}$ \\
\hline 5 & Technical & $\begin{array}{l}\text { Make A Permanent Group 3 } \\
\text { Add More Meeting 1 } \\
\text { Smaller Groups For } \\
\text { Remedy 1 } \\
\text { Clarify Instruction 2 } \\
\text { Add Some Bahasa When } \\
\text { Explaining 1 }\end{array}$ \\
& & 4 \\
\hline 6 & Focus More On Increasing Vocab. E.G Bahas Lirik & 1 \\
\hline 7 & $\begin{array}{l}\text { Add Discussion About Other Aspects/ More } \\
\text { Material To Discuss, E.G. Focus On 1 Topic And } \\
\text { Discuss More }\end{array}$ & \\
\hline & \multicolumn{2}{|c|}{ (Source: Student'slearning perception survey incycle 2) } \\
\hline
\end{tabular}

(Source: Student's learning perception survey in cycle 2) 
As for the students' perception about the method used in the second cycle, analysis of the survey data shows that their overall enjoyment has also exceeded the $70 \%$ threshold, showing a generally positive perception of the task-based learning method in learning English collocations. The obtained grand weighted mean was very close to the first cycle with 3,17 , resulting in 79, $2 \%$ of general enjoyment of the method used. Looking into the detail of the questionnaire items, the task-based learning method was most appreciated by students as it allows them to learn collocations in a more contextual, communicative and collaborative manner. In addition, analysis of the open responses where students offered suggestions shows that 17 of them considered that the method was good and effective in increasing their understanding of English collocations, while 11 of them thought that more active and communicative activities could be added to help them learn collocations better, such as via vocabulary games. Based on the reflection on cycle 2, therefore, the refinement was considered adequate and the researcher stopped the cycle.

\section{Discussion}

The student's performance on the word association test indicated a relationship among aspects including anxiety, collaborative approach, and second language acquisition. Firm evidence has put the anxiety into a highlight to language learning success. It was confirmed that the negative role of the second language (L2) anxiety affected both L2 learning and moderating effects of several (none) linguistic variables (Teumouri, et al, 2019). A similar finding by Sutarsyah (2017) claims that the students' overall speaking performance had been influenced by anxiety. She reported that nervousness was a dominant factor followed by worries and tension. Furthermore, Debio \& Ilankumaran (2018) asserted that the negative reinforcement rooted in less proper training, lack of appreciation, and motivation lead the students to develop inferiority complexes. Thus, they did not get chances to clarify their doubts due to feeling fear and shyness.

In this study, instructors applied a collaborative learning approach to lessen the anxiety. When the anxiety scales down, the language acquisition process improves. The argument falls for the monitor theory by Stephen Krashen (1982). He claims that the benefit of comprehensible input is to produce the expected output and that it must occur in a non-stressful situation. It means that the learners must be previously supported by prior knowledge of language forms and rules as well as plenty of practice hours. In this study, the use of a collaborative approach seems relatively effective to create a supportive atmosphere to bring 
past learning and supportive peers into playing to lessen anxiety and to promote prolonged learning. Therefore, collaborative learning in cycles I and II was found to be proper to facilitate cognitive processes that Debio \& ilankumaran (2018) claimed to be language acquisition, storage, manipulation and transformation of information.

However, a variety of techniques also potentially improves second language acquisition. While collaborative learning approaches are known for several benefits such as reducing language anxiety, raising students' participation and increasing self-confidence (Arta, 2018), technique enrichment also contributes to boosting students' second language acquisition process. Through this study, grammar-translation was applied to both cycles to explain the context and stimulate deeper comprehension. Meanwhile, the communicative approach focuses on rehearsing the students' mental lexicon through real-time interaction and speaking tasks.

Based on the students' language performance in each cycle, mental lexicon processing is influenced by three dimensions namely time exposure, level of comprehension and instructional activities. The longer the students discussed with the instructors and their peers, the better their scores became. Additionally, when the students had been informed well about the language context, they acquired better vocabulary usage and properly identified pair words (collocations). A preference for teaching techniques was also apparent. A variety of tasks in cycle II were found to be more effective to improve the student's score threshold than listening to songs in cycle I. When the instructional activities were developed based on the modified suggestopedia technique by delivering lots of listening activities, although the student's found them relaxing, they had difficulty in decoding the input. As Krashen (1982) claimed about comprehensible input, therefore, the abundance of listening resources did not benefit the students that much for they had a lack of prior knowledge of language rules, forms, and pronunciation.

On the other hand, when the instructional activities were developed using a variety of tasks, the students got plenty of hours to discuss the tasks. They rehearsed several skills at the same time namely, listening comprehension (language context and scaffolding given by the instructor), reading comprehension (Vocabulary and comprehension questions), Speaking (pronunciation and fluency), and writing (summarizing ideas). However, somehow there is a contradictory situation based on the student's perception. It is where the instructor found that the higher the score threshold the students achieved, the less enjoyment they perceived. Based on the students' summary response on perception, they suggested that the frequent use of games was believed to be necessary to improve the quality of teaching and learning in both cycles I and II. This indicates that they need to improve their autonomy and competitiveness in a less 
pressure learning environment yet solid interpersonal engagement persists to achieve the desired learning outcome.

\section{Conclusion}

The study concludes that there is a strong relationship between approaches and second language acquisition. Approaches such as the Collaborative Learning Approach (CLA) and the use of a variety of techniques are useful to lessen anxiety and to improve confidence and participation. Specifically, skill-based tasks facilitate the students to practice the language within the subconscious level through mental lexical activities such as language acquisition, storage, manipulation and transformation of information. Through the modification of time exposure, level of comprehension questions and instructional activities in cycle II the students finally passed the score threshold. Moreover, this study found that reading tasks are a better fit for adult learners than listening tasks to improve their mental lexicon of word association mastery. In general, a collaborative approach is a highly rewarding practice to improve the mastery of vocabulary as well as to create a dynamic and supportive learning environment.

The limitation of the study includes the use of CLA in the EFL context during the online mode, and the discussion only focuses on the syntax of CLA about Second Language Acquisition. Hopefully, future research can offer more ambitious examinations on how specific language input is stored longer than the other and also about techniques to promote prolonged learning.

\section{Acknowledgement}

We would like to send our gratitude to Dr Muhammad Mashuri and Ibu Nurul Widyastuti, PhD for their effort to value the research and to provide facilities for learning, research and development in Language and Culture Hub, Institut Teknologi Kalimantan.

\section{REFERENCES}

Arnold, N., \& Ducate, L. (2019). Engaging language learners through CALL: From theory and research to informed practice (Advances in CALL research and practice). Bristol, UK: Equinox Publishing Ltd.

Arta, B. (2018). Multiple Studies: The Influence of Collaborative Learning Approach on Indonesian Secondary High School Student's English Speaking Skill. English 
Language Teaching Educational Journal, 1 (3), 149-160.

https://doi.org/10.12928/eltej.v1i3.143

Barkley, E. F., Major, C. H., \& Cross, K. P. (2014). Collaborative learning techniques: A handbook for college faculty. San Francisco, CA: Jossey-Bass.

Carroll, David W. 2008. Psychology of Language, 5th ed. Thomson USA: Wadsworth.

Dooly, M., \& Sadler, R. (2016). Becoming little scientists: Technology-enhanced projectbased language learning. Language Learning \& Technology, 20(1), 54-78.

Hidayati, Nurul Ulfi. 2010. Improving Students' Ability in Writing Procedure Text Using Realia (A Classroom Action Research with The Students of Grade VIIG at SMP N 18 Semarang in The Academic Year of 2010/2011).Published Thesis. Semarang: Institut Agama Islam Negeri Walisongo

Mohamed, M. N. A., Ngadiran, N. M., Abd Samad, N., \& Powzi, N. F. A. (2020). English Language Learning Beyond the Borders: Constructing E-Collaborative Learning between Students of Different Regions. Universal Journal of Educational Research, 8(5A), 108-113. https://doi.org/10.13189/ujer.2020.081916

Pattanpichet, F. (2011). The effects of using collaborative learning to enhance students' English speaking achievement. Journal of College Teaching \& Learning (TLC), 8(11), 1-10. https://doi.org/10.19030/tlc.v8i11.6502

Peppard, J. 2007. 'Exploring the Relationship between Word-Association and Learners' Lexical Development'. Center for English Language Studies: University of Birmingham.

Robinson, H., Kilgore, W., \& Warren, S. (2017). Care, communication, support: Core for designing meaningful online collaborative learning. Online Learning Journal, 21(4). https://doi.org/10.24059/olj.v21i4.1240

Reychav, I., \& McHaney, R. (2017). The relationship between gender and collaborative learning assessment in a mobile technology-based setting: An empirical investigation. Comput. Educ, 113, 61-74. https://doi.org/10.1016/j.compedu.2017.05.005

Salcedo-Lagos, Pedro. Morales-Candia, Sergio. Fuentes-Riffo, Karina. Rivera-Robles, Susan. Sanhueza-Campos, Cristian. (2021). Teachers' Perceptions Analysis on Students' Emotions in Virtual Classes during COVID19 Pandemic: A Lexical Availability Approach. Sustainability, 13 (6413). https://doi.org/10.3390/su13116413

Salma, N. (2020). Collaborative learning: An effective approach to promote language development. International Journal of Social Sciences \& Educational Studies, 7(2), 57-61. https://doi.org/10.23918/ijsses.v7i2p57 
So, H.-J., \& Brush, T. a. (2008). Student perceptions of collaborative learning, social presence and satisfaction in a blended learning environment: Relationships and critical factors. Computers \& Education, 51(1), 318-336. http://doi.org/10.1016/j.compedu.2007.05.009

Sutarsyah, C. (2017). An Analysis of Student's Speaking Anxiety and its Effect on Speaking Performance. Indonesian Journal of English Language Teaching and Applied Linguistics, 1(2). https://doi.org/10.21093/ijeltal.v1i2.14

Teimouri, Y., Goetze, J., Plonsky, L. (2019). Second Language Anxiety and Achievement: Meta-Analysis. Journal of Studies of Language Acquisition, 41 (2). https://doi.org/10.1017/S0272263119000445

Tsai, P. (2019). Beyond self-directed computer-assisted pronunciation learning: A qualitative investigation of a collaborative approach. Computer Assisted Language Learning, 32(7), 713-744. 10.1080/09588221.2019.1614069

Vygotsky, L. S. (1980). Mind in society: The development of higher psychological processes. Cambridge, MA: Harvard University Press. https://doi.org/10.2307/j.ctvjf9vz4

Wentzel, K. R., \& Watkins, D. E. (2002). Peer relationships and collaborative learning as contexts for academic enablers. School Psychology Review, 31(3), 366-378. https://doi.org/10.1080/02796015.2002.12086161

Wong, J., Baars, M., Davis, D., Van Der Zee, T., Houben, G. J., \& Paas, F. (2019). Supporting self-regulated learning in online learning environments and MOOCs: A systematic review. International Journal of Human-Computer Interaction, 35(4-5), 356373. https://doi.org/10.1080/10447318.2018.1543084 